\title{
Cultural Landscapes Link to Nature: Learning from Satoyama and Satoumi
}

\author{
Maya Ishizawa \\ World Heritage Studies, University of Tsukuba, Tsukuba, Japan \\ Email: ishizawa.maya@gmail.com
}

\begin{abstract}
The nature-culture divide is an artificial separation consolidated by Western modern science. It is a social construction that disseminated globally, but does not exist in some non-Western societies. Abandoning this framework to embrace an integrated system for sustainability is challenging. The concept of the Historic Urban Landscape (HUL) already attempts to integrate natural and cultural heritage into urban planning by focusing on a landscape approach. However, this approach consumes rural and nature into the urban. To uncover nature and return it to the forefront of urban conservation, this paper explores cultural landscapes as examples where natural and cultural values are inextricably related. Four case studies are presented of satoyama and satoumi, cultural landscapes of Japan where Shinto beliefs and traditional agricultural practices knit together nature and culture, rendering the divide unseen. This paper suggests connecting the HUL approach, with this inclusive understanding, by turning the focus to mapping seasonal relationships following a transdisciplinary approach in which indigenous and local knowledge are integrated, as well as a temporal dimension. In this way, one can find satoyama and satou$m i$ in the urban environment: by looking beyond the attributes, the interrelationships with the natural substratum needed to support the development of quality and resilient environments can be revealed.
\end{abstract}

KEYWORDS cultural landscapes, satoyama, satoumi, Historic Urban Landscape, sustainability, reconnecting nature-culture, natureculture, nature-culture divide, intangible cultural heritage

Received September 13, 2018; accepted November 26, 2018.

\section{Introduction}

Cities are growing at a rapid pace, and much of this uncontrolled development produces low-quality environments, poverty, and environmental pollution. This creates unsustainable living conditions for the majority of the human population. If this trend continues, almost twothirds of all people may be living in urban environments by 2050 (United Nations 2018), and a much of this will be under challenging conditions.

To redirect this trend and work on designing and planning inclusive, safe, resilient and sustainable cities and human settlements, as stated in Sustainable Development Goal 11-SDG 11 (United Nations 2015), UNESCO Recommendation on the Historic Urban Landscape (UNESCO 2011) suggests integrating cultural and natural heritage into urban planning. Cultural and natural heritage bring identity and diversity, supporting community and wellbeing. As heritage researchers and practitioners who intend to contribute to the sustainability of our urban environments while conserving heritage, we need to look at the synergies between the Historic Urban Landscape (HUL) approach, 2016 UN Habitat New Urban Agenda (NUA) and 2015 UN Agenda 2030 for Sustainable Development (United Nations 2015), especially but not exclusively, their connection with SDG 11, Target 4: Strengthen efforts to protect and safeguard the world's cultural and natural heritage.

In these three international documents, which differ in nature and scope, can be found the urgent need to change the current mindset that led us to rapid and inadequate urbanisation, exhaustion of natural resources, environmental pollution and, furthermore, to climate change. All three of these instruments are intended to integrate nature and consider the important role it plays in human survival and sustainability. As the future of humanity will tend to be urban (United Nations 2015, 2018), the highly 
important action that needs to be taken is to question our relationship with nature and turn urbanisation into a tool for developing healthier human settlements.

A group of scientists has proposed that the scale of human activities' impact on the planet deserves a place in the Earth's history, and that we are living in a new epoch, the Anthropocene, wherein humans are recognised as having a powerful geological force, capable of altering Earth system processes including atmospheric, biospheric and hydrologic. Malhi (2017) reviews how the existence and beginning of the Anthropocene has become an interesting debate involving natural and social scientists. The concept of the Anthropocene invites us to question our relationship with nature because it represents the 'defeat' of nature, with humans capable of transforming Earth processes at a global scale. Even though the starting point has not been agreed upon, and is not located in the Industrial Revolution, it is the point of time at which humans accelerated processes of depletion and exhaustion of fossil resources without considering the impacts and long-term effects of environmental pollution, and the progressive destruction of ecosystems on which human life depends. This approach to nature, with a long evolution further developed by Western modern science based on distinction of humans from their natural environment, has established an essential delineation of nature and culture. Urbanisation and urban sprawl are among the major impacts of this process, of this defeat. They are also major drivers of landscape change.

Currently, our relationship with nature is mostly utilitarian, wherein cities use the largest percentage of natural resources available (United Nations 2017), and in the process are creating large amounts of unrecyclable waste that ends up in our oceans, underground, in the air we breathe, and in the food we eat. Therefore, means of reencountering nature, of working with nature again in our daily urban lives, are the key questions that need to be urgently addressed.

This paper proposes a beginning by looking at the root of this unbalanced relationship, namely, the Western Modern Paradigm (Berque 2013), Modern Constitution (Latour 1993) or naturalist ontology (Descola 2005) built on the dichotomy between nature and culture. It discusses the embedded nature-culture divide that promotes our alienation from nature and leads us to produce unsustainable living environments. Further, it proposes reconnecting nature and culture in application of the HUL approach and in our understanding of heritage in general. The author explores the nature-culture divide to critically analyse the role of nature in international instruments, and considers how the idea of reconnecting nature and culture is evolving in the field of heritage conservation. As an example of a non-Western worldview, four case studies from landscapes in Japan apply the concept of satoyama, in which nature and culture are inextricably related, and heritage values appear as fourth-dimensional, taking roots in holistic understandings of dwelling. In closing, this paper suggests how this understanding can be used to identify layers reconnecting nature and culture in urban settings, and apply that unity to urban environments.

\section{The Nature-Culture Divide}

The nature-culture divide is an artificial separation consolidated by Western modern science, a social construction that has been disseminated globally as a convention, but that does not exist in some non-Western societies, as has been shown by the work of many ethnologists and anthropologists, such as Philippe Descola (2005). The absence of a divide for some societies has become more evident by way of acknowledgement of the different ways of life and systems of knowledge of indigenous peoples through international platforms such as the Intergovernmental Platform on Biodiversity and Ecosystem Services (IPBES), United Nations Permanent Forum on Indigenous Issues and the Local and Indigenous Knowledge Systems Program (LINKS) at UNESCO and the Convention on Biological Diversity of 1992 (CBD). In the heritage field, the Convention on the Safeguarding of Intangible Cultural Heritage of 2003 (ICH), and the progress in the implementation of the Convention on the Protection of the World Natural and Cultural Heritage of 1972 (World Heritage Convention), with the inclusion of cultural landscapes categories, and the Free, Prior and Informed Consent (FPIC), as well as the Nara Document on Authenticity (1994), have invited different ways of understanding heritage and, consequently, the diversity of understandings of the relationship between what we usually call culture and nature. All these agreements and documents have contributed to mainstreaming that there are a variety of conceptions of nature, and not every culture understands nature in the same way that Western sciences have established hegemonically.

The idea that 'nature' has an objective reality is based on development of Western philosophy and has been consolidated by the scientific method. Though the question of the nature-culture divide has been mostly debated in anthropology, the author, not being an anthropologist, is applying certain ideas from social scientists that may help 
elucidate how this divide causes unsustainable urban environments, and how it reflects on the division between natural and cultural heritage in our field of practice. Berliner et al. explain the concept of the 'Modern Constitution' proposed by French sociologist Bruno Latour, that rules our globalised society as follows:

The Modern Constitution is guided by a particular metaphysics that leads its followers to believe that nature is the given reality 'out there', independent of human passions and politics. In other words, the Moderns take nature to be the default setting of life and being, and to know nature is to hold the key to indisputable truth and the real (Berliner, Legrain, and Van de Port 2013, 440).

The 'Moderns', as Latour calls the followers of this ontology, apply such a defined separation between human and non-human, assessing the latter as objects, and intending to void their analysis from any subjective bias. However, reaching an understanding of the world without having a 'human bias' of it is an impossible task, and in this sense, attempting to restrict our relationship with the 'things' and spaces with which and where we live disconnects us from the magic, from the myth, and our ancestors' traditions, drying up and mechanising our ways of life. This modernisation of daily life and urban environments is now reflected in the concept of the 'smart city', a notion of automation and clean efficiency that may ignore the particularity of different social and cultural environments, as promoted by the NUA.

Philippe Descola (2005) proposes four ontologies that define the relationship between the human and the nonhuman. Naturalism, at the root of the nature-culture divide, emphasises a physical continuity and spiritual discontinuity between the human and the non-human. Other non-Western or pre-modern cultures, he notes, correspond to one of the other three ontologies: animism (spiritual continuity and physical discontinuity), totemism (human and non-human are descending from the same ancestor, and there is both continuity at the physical and spiritual levels), and analogism (discontinuity both at physical and spiritual levels). Each of these other ontologies arranges the world and the relationship between humans and non-humans differently from the Western modern naturalist approach. Feenberg (2013), in his analysis of Descola's proposal, explains:

... [O] ur experience of nature and of ourselves has been progressively separated from everything that allows us to establish continuities and connections between our spirit and things of the natural world. ... Appearance and reality are opposed to one another. The subject of knowledge of nature takes itself as external to nature, scaled down to be just raw material (...). As long as modern societies inscribe this force in their mentalities and their institutions, they undermine their own foundation within the natural world (Feenberg $2013,115)^{1}$.

French ethno-ecologist Serge Bahuchet (2017) explains the opposition that has resulted between anthropology and ecology in relation to nature: anthropologists, experiencing the diversity of human ontologies, as described by Descola, postulate nature's non-existence, because different cultures will experience the non-human in different ways. Nature is then a creation from Western science, and ecologists consider humans as destroying nature (Bahuchet 2017). The latter position is based on the naturalist ontology, and the scientific approach in which nature is understood as a clearly defined entity separated from humans. This approach is reflected in our understanding of heritage and the division between cultural heritage and natural heritage. Natural heritage practitioners and researchers, many of whom are conservation biologists and ecologists, would postulate the existence of a pristine nature that needs to be protected from human hands. However, the encounter with indigenous cultures that have modified, and continue to modify, their natural environment has brought into question the existence of 'untouched nature', with some researchers of the topic of nature conservation acknowledging the importance of interactions between humans and natural environments for producing and conserving biodiversity (Orlove and Brush 1996; Denevan 2001; Bahuchet 2017). From another perspective, cultural heritage practitioners have inherited principles of conservation debated in the Enlightenment, and based on Western thought, and Western classical history, mostly focused on a material culture and the need to preserve the material past (Jokilehto 1999; Smith 2006). Nevertheless, with the implementation of the 2003 Convention that brought recognition to intangible cultural heritage, and the adoption of the 1972 Convention by countries other than those in Europe or that have strong and distinct traditions, these ideas have come into question. Cultural heritage practitioners now have trouble proposing a unique strategy for conservation of the past, as reflected in the buildings, land use systems of the present, and traditions from different cultures around the globe that are changing while moving into the future. Additionally, the progressive loss of cultural heritage, natural 
heritage and the negative effects of rapid urbanisation are all related to the nature-culture divide and its roots in modern science, which globally has brought about the idea of 'development': 'The universality of science finds its limits in the evils that accompany development in the world, the most evident being pollution and urban misery'. (Feenberg 2013, 115)

Many efforts have been taken to introduce culture and recognise its role as a driver and enabler of sustainable development (United Nations General Assembly 2010; UNESCO 2012), and as a resource for urban planning (UNESCO 2016). It is even mentioned clearly in the NUA: '10. The New Urban Agenda acknowledges that culture and cultural diversity are sources of enrichment for humankind and provide an important contribution to the sustainable development of cities, human settlements and citizens, empowering them to play an active and unique role in development initiatives.' (United Nations 2017, 4)

However, because of our intrinsic interdependence with it, the role of nature is still not sufficiently emphasised. In the following section, this paper analyses the role conferred upon nature in the international instruments we are dealing with, with the aim of showing how this understanding of nature follows the distinction based on the naturalist ontology.

\section{Nature in the Agenda 2030, the NUA and the HUL Recommendation}

As mentioned, the nature-culture divide is reflected in the conception of institutional organisations and international policy where there is a separation between the nature and culture sectors, natural heritage and cultural heritage, and urban and rural. For instance, we can examine how 'nature' is presented in the Agenda 2030 or in the NUA. Natural elements are seen as resources that we need to conserve and sustainably use (see Box 1, SDG 14 and 15). Nature becomes 'natural heritage' (see Box 1, SDG 11 Target 4). Furthermore, nature is seen as a resource, but also as a threat ('natural disasters', SDG 13). In the NUA, urbanisation is now being observed as a tool for environmental protection, wherein urban planning can be used for protecting nature, but also for protecting us from it (see Box 2, 14 (c)). Nature is 'environment', it is 'ecosystem,' and 'environmental' qualifies several of the elements that make up 'nature. The NUA is an attempt to control and manage the effects of the Anthropocene, understanding the current human mindset as detrimental for the environment, and therefore following the separation between nature and culture.
SDG 11: Make cities and human settlements inclusive, safe, resilient and sustainable.

Target 11.4 Strengthen efforts to protect and safeguard the world's cultural and natural heritage.

SDG 13: Take urgent action to combat climate change and its impacts.

Target 13.1 Strengthen resilience and adaptive capacity to climate-related hazards and natural disasters in all countries.

SDG 14: Conserve and sustainably use the oceans, seas and marine resources for sustainable development.

SDG 15: Protect, restore and promote sustainable use of terrestrial ecosystems, sustainably manage forests, combat desertification, and halt and reverse land degradation and halt biodiversity loss.

Box 1 Nature in the Agenda 2030 (Source: United Nations 2015).

In the UNESCO Recommendation on the Historic Urban Landscape, nature is described as a geographical setting, and surroundings, but also as underlying values (see Box 3). The HUL concept seems an attempt to transcend the division between urban and rural by bringing a landscape approach and following the geological idea of layering, and therefore, to look at what is 'under,' and uncover nature in relation to human inhabitation, using a territorial scope. However, HUL still consumes the rural and the natural in the urban. So then how is nature given a place?

These three instruments clearly discuss a nature that is external and separated from humans, that needs to be sustainably managed and used and, even more, a nature that serves humans through [natural] resources and [ecosystem] services. The concept of ecosystem services, set out with the Millennium Ecosystem Assessment (2001-2005) as provisioning, regulating, supporting and cultural (Millenium Ecosystem Assessment 2005), intends to place an economic value on the relationship between humans and nature. The initiative aims to acknowledge the value of nature for sustainable human living, nevertheless objectifying cycles of life and following an anthropocentric view. These initiatives and instruments illustrate how the nature-culture divide is embedded and is a challenge that needs to be overcome.

\section{Reconnecting Nature and Culture in Heritage Conservation}

The need to reconnect nature and culture, and humans to nature, have grown increasingly evident in recent years; 
5. By readdressing the way cities and human settlements are planned, designed, financed, developed, governed and managed, the New Urban Agenda will help to end poverty and hunger in all its forms and dimensions; reduce inequalities; promote sustained, inclusive and sustainable economic growth; achieve gender equality and the empowerment of all women and girls in order to fully harness their vital contribution to sustainable development; improve human health and wellbeing; foster resilience; and protect the environment.

13. (h) Protect, conserve, restore and promote their ecosystems, water, natural habitats and biodiversity, minimise their environmental impact and change to sustainable consumption and production patterns.

14. (c) Ensure environmental sustainability by promoting clean energy and sustainable use of land and resources in urban development, by protecting ecosystems and biodiversity, including adopting healthy lifestyles in harmony with nature, by promoting sustainable consumption and production patterns, by building urban resilience, by reducing disaster risks and by mitigating and adapting to climate change.

Environmentally sustainable and resilient urban development

65. We commit ourselves to facilitating the sustainable management of natural resources in cities and human settlements in a manner that protects and improves the urban ecosystem and environmental services, reduces greenhouse gas emissions and air pollution and promotes disaster risk reduction and management, by supporting the development of disaster risk reduction strategies and periodical assessments of disaster risk caused by natural and human-made hazards, including standards for risk levels, while fostering sustainable economic development and protecting the well-being and quality of life of all persons through environmentally sound urban and territorial planning, infrastructure and basic services.

Box 2 Some excerpts showing Nature in the New Urban Agenda (Source: United Nations 2017).

5. ... It suggests a landscape approach for identifying, conserving and managing historic areas within their broader urban contexts, by considering the interrelationships of their physical forms, their spatial organisation and connection, their natural features and settings, and their social, cultural and economic values.

8. The historic urban landscape is the urban area understood as the result of a historic layering of cultural and natural values and attributes, extending beyond the notion of 'historic centre' or 'ensemble' to include the broader urban context and its geographical setting.

9. This wider context includes notably the site's topography, geomorphology, hydrology and natural features, its built environment, both historic and contemporary, its infrastructures above and below ground, its open spaces and gardens, its land use patterns and spatial organization, perceptions and visual relationships, as well as all other elements of the urban structure. It also includes social and cultural practices and values, economic processes and the intangible dimensions of heritage as related to diversity and identity.

11.... It is rooted in a balanced and sustainable relationship between the urban and natural environment, between the needs of present and future generations and the legacy from the past.

21. Modern urban conservation policies, as reflected in existing international recommendations and charters, have set the stage for the preservation of historic urban areas. However, present and future challenges require the definition and implementation of a new generation of public policies identifying and protecting the historic layering and balance of cultural and natural values in urban environments.

Box 3 Some excerpts showing Nature in the Recommendation on the HUL (Source: UNESCO 2011) (Source: United Nations 2017).

however, finding the way to reconnect remains a difficult endeavour. In the field of heritage conservation, especially in the World Heritage context, the idea of 'linking nature and culture' is gaining momentum with the Nature/Culture and Culture/Nature Journeys ${ }^{2}$ as well as the Connecting Practice Project, partnership between the International Union on the Conservation of Nature (IUCN) and the International Council on Monuments and Sites (ICOMOS) (IUCN and ICOMOS 2015), and Nature-Culture Capacity
Building Programs (Ishizawa, Inaba, and Yoshida 2017; Court and Wijesuriya 2015). At an international level, there are several programs and initiatives bridging the gap between natural and cultural heritage (Aprile, Doubleday, and Gibson 2015). Nevertheless, this is a complex task, as we deal with different scientific disciplines, and with different cultural worldviews. Though the possible synergies are evident, use of terms and finding a common framework are challenging. Inclusion of the category of cultural 
landscapes in the Operational Guidelines of the World Heritage Convention in 1992 brought a revolution in the nomination processes and in the perception of what cultural heritage is, as well as a necessary look toward the natural values engaged in the generation and continuity of cultural landscapes (Rössler 2006). In the natural science sector, the UNESCO Man and the Biosphere Programme was launched in 1971 to designate biosphere reserves (BRs). BRs define natural protected areas and their surroundings, with the protected areas working as cores for conserving biodiversity, supporting the sustainable development of the inhabited areas around them, and becoming research laboratories. The BR concept went against the classical idea that humans need to be separated from natural areas, and instead proposed their relationship should be reinforced by forging new connections between natural areas and the population living nearby, creating sustainable development through tourism, eco-tourism, agro-forestry and other activities that had declined because of urban migration and desertification of rural areas (Ishwaran, Persic, and Hoang Tri 2008; Araya Rosas and ClüsenerGodt 2010; Reed and Massie 2013). Ramsar sites are designated areas that stem from the Convention on Wetlands, often known as the Ramsar Convention, established in 1971. The purpose is to promote the conservation and sustainable use of wetland areas and the habitat they provide for certain species. Ramsar sites also deal with the relationship between humans and nature, similarly to BRs, considering the importance of the population living in the wetlands and taking these people as the principal stewards of their resources. The IUCN Protected Landscapes and Seascapes is a category (Category V) of management the IUCN proposed for areas that represent interrelations between nature and humans, highly similar to the category of cultural landscapes of the World Heritage Convention, but seen from the natural heritage perspective, dealing with productive landscapes that also provide for and sustain biodiversity (Borrini-Feyerabend et al. 2013). The United Nations Food and Agriculture Organisation (FAO) in 2002 also created a designation called Globally Important Agricultural Heritage Systems (GIAHS), which overlaps with the World Heritage Cultural Landscapes and the IUCN-protected landscapes and seascapes in the sense it focuses on recognition of traditional and continuing productive systems with heritage value, and with importance for food security and maintenance of biodiversity (FAO 2017). However, unlike the World Heritage Cultural Landscapes, that need to justify an outstanding universal value, which includes proving integrity and authenticity, with a strong emphasis on visual and aesthetic perspectives, the GIAHS focus is on continuation of historical agricultural livelihoods in rural areas, which contributes to the regeneration of biodiversity. UNESCO and FAO recently renewed their partnership to include synergies between the World Heritage Convention and GIAHS and to co-operate on identification and safeguarding of elements of living heritage related to agricultural heritage systems. Concurrently, the IUCN and ICOMOS are partnering with GIAHS in the Connecting Practice Project to focus on management of agricultural landscapes with natural and cultural values in the framework of the World Heritage system. This is a step in the right direction.

Apart from these steps, and relevant to the urban discussion, are the Urban Biosphere Reserves and the Urban Protected Areas. These are working concepts. One refers to application of the BR goals and zoning into urban areas ${ }^{3}$, and the second refers to protected areas, of any management category (as defined by IUCN), that are located in or adjacent to urban areas. The problem with these concepts is that they are also based on the nature-culture divide and the idea of a natural area working as a core of biodiversity conservation. The delineation of strictly protected nature is difficult, and managing the hybridity that occurs in urban areas, as well as applying conservation regulations, has posed challenges for adapting these concepts to these frameworks. Nevertheless, urban protected areas are being recognised (Trzyna et al. 2014) and urban BRs are being designated (though not yet including urban areas) ${ }^{4}$, to also raise awareness about nature conservation among the urban population.

All these designations and programs are already aiming at reconnecting nature and culture, and focusing not only on cultural or natural values, but also on their interrelations. However, the divide persists, especially in the legal systems and institutions in charge of enforcing these designations.

\section{Learning to Reconnect: A Japanese Experience}

The case of Japan is presented here as an example of a conservation system that follows the nature-culture divide at an institutional level, but not necessarily at a conceptual level. In Japan, the Ministry of the Environment is in charge of natural heritage and the Agency for Cultural Affairs, belonging to the Ministry of Education, Culture, Sports, Science and Technology, is in charge of cultural heritage. Cultural landscapes, natural monuments, places of scenic beauty, and intangible cultural properties are all 
categories described in the "Law for the Protection of Cultural Property" (1950), and these show understandings of interrelations between cultural and natural values from the culture sector. In the case of the nature sector, national parks, a designation that began in 1930, includes private and public land, as well as areas that are not strictly 'pure nature,' but rather are occupied, sometimes by temples and shrines (i.e. cultural heritage).

In the context of the CBD talks in 2009, the Ministry of the Environment and United Nations University (UNU) launched the Satoyama Initiative, an international partnership applying the local concept of satoyama to define productive landscapes that have cultural and natural value, and are important for the conservation of biodiversity (NCB 2009), also connected to the GIAHS concept ${ }^{5}$. Both GIAHS and the Satoyama Initiative relate to the CBD and, thus, their core is biodiversity conservation through traditional agricultural practices. In translating this term to international scientific language, satoyama became a socio-ecological system. Some now accept satoyama as describing agricultural landscapes that integrate traditional ways of life in harmony with nature where agro-forestry is the predominant economic activity (Takeuchi 2003).

The satoyama concept is, however, seen as coming from the nature sector, and in the culture sector satoyama is called cultural landscape. In 2004, the Landscape Law was passed, allowing Japanese prefectures and municipalities to designate areas for protection based on their landscape value; either aesthetical, historical, or ecological. In 2005, the "Law for the Protection of Cultural Properties" was modified to integrate the designation of Important Cultural Landscapes: 'Landscapes that have developed in association with the lifestyles and livelihoods of the people together with the local features, which are indispensable to the understanding of the lifestyles and livelihoods of the people of Japan.' (Agency for Cultural Affairs 1950, chap. III)

This excerpt shows the focus of the culture sector is on lifestyles and livelihoods, whereas the nature sector is more concerned with conserving the biodiversity that these socio-ecological systems provide.

\section{Satoyama and Satoumi}

Nevertheless, for people who live within the landscapes, there is no separation of lifestyle and biodiversity. The case of satoyama and satoumi illustrates relationships between communities of people, animals, plants and all non-human elements, as well as their interactions. Interpreted by sciences, this system is based on an ecosystems approach, intending to include people and their relationships with the environment, forming a larger ecosystem of humans with nature. More than $40 \%$ of Japan is satoyama or satoumi (Duraiappah et al. 2012, 3), and it represents a historical model for environmental stewardship and sustainable resources management.

For local people, satoyama (village and mountain) means 'neighbouring forest' and satoumi (village and sea) is the 'neighbouring sea.' These terms have traditionally referred to mountain forests. In these landscapes, 'animist traditions,' rooted in Shinto beliefs that assign agency to non-human elements, represent understandings where the divide makes no sense. Shinto could be observed as following an animistic ontology, in the terms of Descola. Nevertheless, it is a complex worldview that integrates not only 'nature' but also climate and time.

\section{Seasons and Time}

In his interpretation of Japan, Augustin Berque recognises the complexity of the climate in this archipelago as a defining feature for the people's worldview:

As a whole, Japan's climate is a combination of blessings and violence. Blessings of high warmth and humidity in summer, which favour an exuberant vegetation unknown in Europe; at the same time, afflictions from potential deluges with unparalleled power. Typhoons are often destructive, and at the same time necessary, because of the water they bring. Likewise, the thickness of the snowpack on the mountains is the best water reservoir for the rice paddies, but also devastating (such as during the spring melt). Japanese civilisation is inseparable from this climate, which has allowed the extension of rice cultivation to almost all its territory (Berque 1976, 15). ${ }^{6}$

This idea refers to the term fûdo (風土, wind and land) as used by Tetsuro Watsuji (1988), and reinterpreted by Berque $(2001,2013)$. Berque also recaptures the importance of the seasons, in which a landscape differs depending on the time of year, as many of its characteristics change, resulting in a different place. This has been emphasised in Japanese art and poetry:

What the French would call brume (mist), brouillard (fog), the Japanese would call kiri or kasumi. Metereologically, both phenomena are more or less identical; however, kiri can only be used in relation to autumn, and kasumi to spring, in that they are respectively season words. So then, why distinguish between them? 
This is for the good reason that a spring landscape is not an autumn landscape, nor is it a whole, and neither look at each of their elements. Most connotations of kiri or kasumi are indeed diametrically opposed: the first are tinged with melancholy (kiri recalls the departure, the travel, the end of love ...), the latter is coloured by the joy of living. (Berque 2001, 2013) ${ }^{7}$

This idea is coined by the term kigo ( 季語, season word), which refers to seasonal terms, contained in the Saijiki (歳時記, almanac of seasonal words), written and used by poets. In its complexity, Japanese landscape is about spiritual values, agriculture, forestry and poetry. To understand Japanese landscape, the connections between nature and culture need to be comprehended.

\section{Reconnecting Nature and Culture through Capacity Building}

In the framework of the capacity-building workshops organised by the UNESCO Chair on Nature-Culture Linkages in Heritage Conservation at the University of Tsukuba (CBWNCL), landscapes are looked at as examples in which natural and cultural values are inextricably related. Separations have been found to lie at institutional levels, but at community and local levels, where holistic visions prevail, such strict divisions do not exist. The links between nature and culture are found in people and their practices, and indigenous and local knowledge play an essential role. Moreover, in interdisciplinary and transdisciplinary approaches, the workshops explore exchanging methods between social scientists and natural scientists, as well as indigenous people and local stakeholders.

Four rural examples visited during these workshops (CBWNCL 2016 and CBWNCL 2017) are summarised below. In these, the distinction between nature, culture, tangible and intangible is not relevant, and the indivisibility of nature and culture can be observed. Even though, as previously explained, the satoyama concept is mostly used by nature conservationists, many cultural practices are part of satoyama; therefore, here, satoyama is looked at from a nature-culture perspective.

This paper looks at the main attributes that function as carriers of value in places where nature and culture cannot be separated: the roofs, terraces, ritual and pilgrimage routes and sacred sites. These elements represent networks of interactions between the human and the non-human; natural elements such as forests that provide materials, or soil shaped to form terraces, and the technology that allows the human group to appropriate and

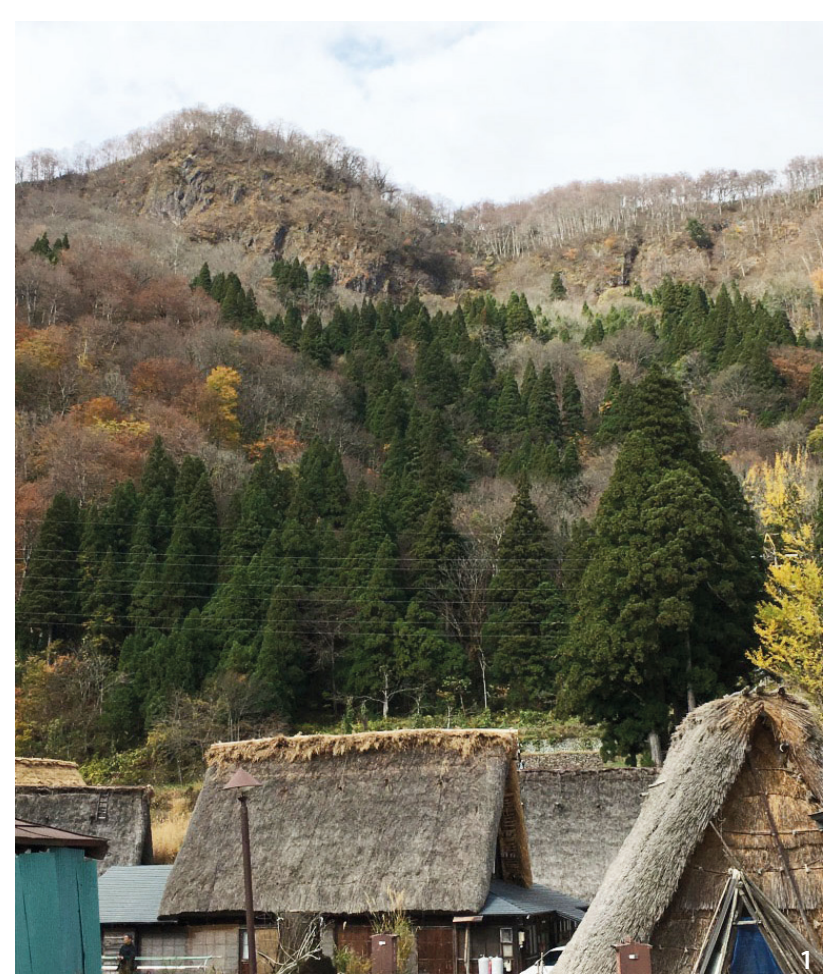

Figure 1 Roofs in Ogimachi village, Shirakawa-go (Source: the author).

make use of these elements. The ritual is held as a performance that involves the human and the non-human in a highly concrete situation of exchange, and where the distinction between material and immaterial blurs. Pilgrimage routes and sacred sites represent footprints of this relationship between the human and the non-human, left in a material form that changes with the seasons and with the passage of time, while being regenerated by new steps and new prayers.

1. Gassho-zukuri, the roofs of Shirakawa and Gokayama The first case is gassho-zukuri, building of steep thatched roofs of the houses in Shirakawa-go and Gokayama, a World Heritage Cultural Landscape since 1995, and which also belongs to the Biosphere Reserve Mount Hakusan since its extension in 2016 (Figures 1, Figure 2). These roofs form part of satoyama, a landscape of village, mountain and agroforestry, in an area of heavy and prolonged winter snowfall. These roofs have been designed to withstand and protect homes from the snowfall, using materials provided by the surrounding forests. In the resulting space, raising of silkworms was developed and these roofs became homefactories for silk production until the industry's decline after the 1960s. Construction and maintenance of these roofs requires communal efforts, and these events reunite the villagers. However, currently, this maintenance must be performed by officers and volunteers, owing 


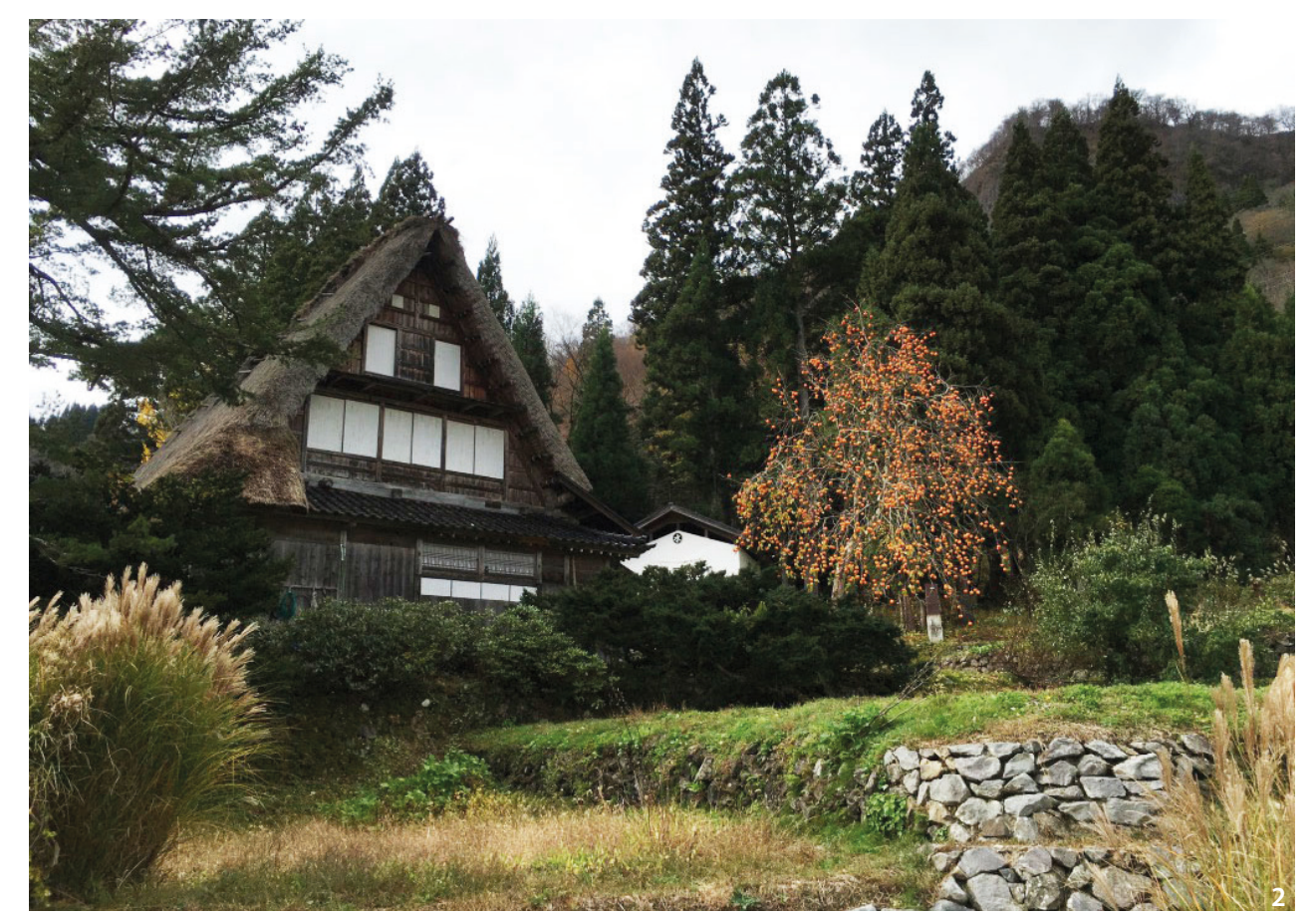

Figure 2 House in Ainokura Village, Gokayama (Source: the author).

Figure $3 a$ and $3 b$ Rice terraces in Shiroyona Senmaida, Noto
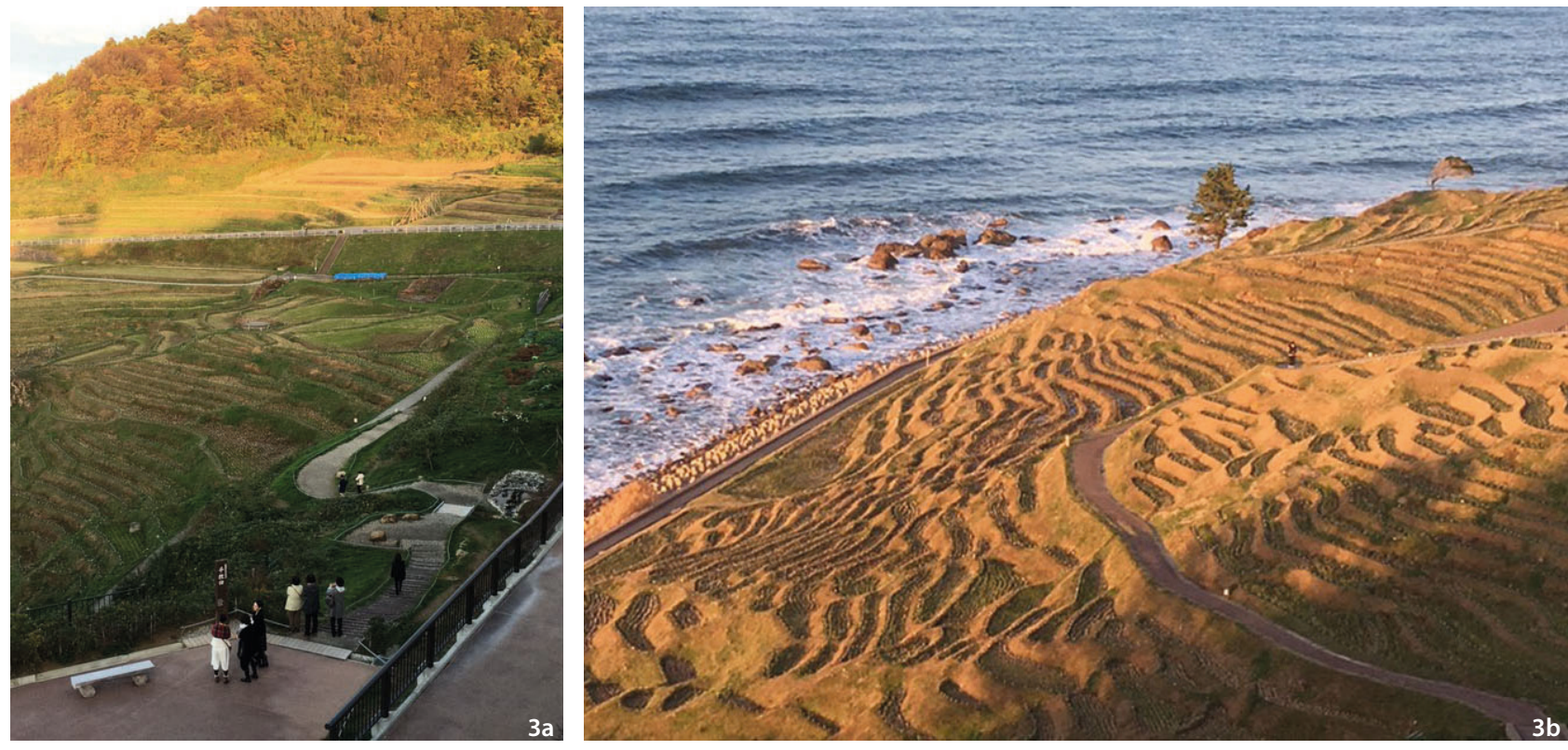

to the trend of depopulation trend in rural Japan. Roof thatching takes place every 15 years, with each side of the roof taking two weeks to be thatched.

2. The terraces of Shiroyone Senmaida

A second example is the rice terraces of Shiroyone Senmaida, a 'place of scenic beauty' since 2011 and located in the FAO GIAHS-designated Noto Peninsula (Figure 3a, Figure 3b). These terraces represent a satoumi landscape of mountain, village and sea. Unfortunately, at the time of the designation, this village only had 11 remaining households. Currently, events that reunite people from the neighbouring cities and the locals, organised by the municipality, help the rice planting and harvest through volunteering. This shows the heritage community can be expanded, and not limited to local people.

3. Aenokoto in Noto Peninsula

The third example is the Aenokoto festival traditional to the Noto Peninsula. This is a ritual performed twice a year to worship the deities of the rice fields for good growth and abundant harvest, and is inscribed in 2009 in the UNESCO Representative List of Intangible Cultural Heritage of Humanity. The ritual tells a story that integrates the climate, biodiversity, food security and spirituality, while bringing together the community: 


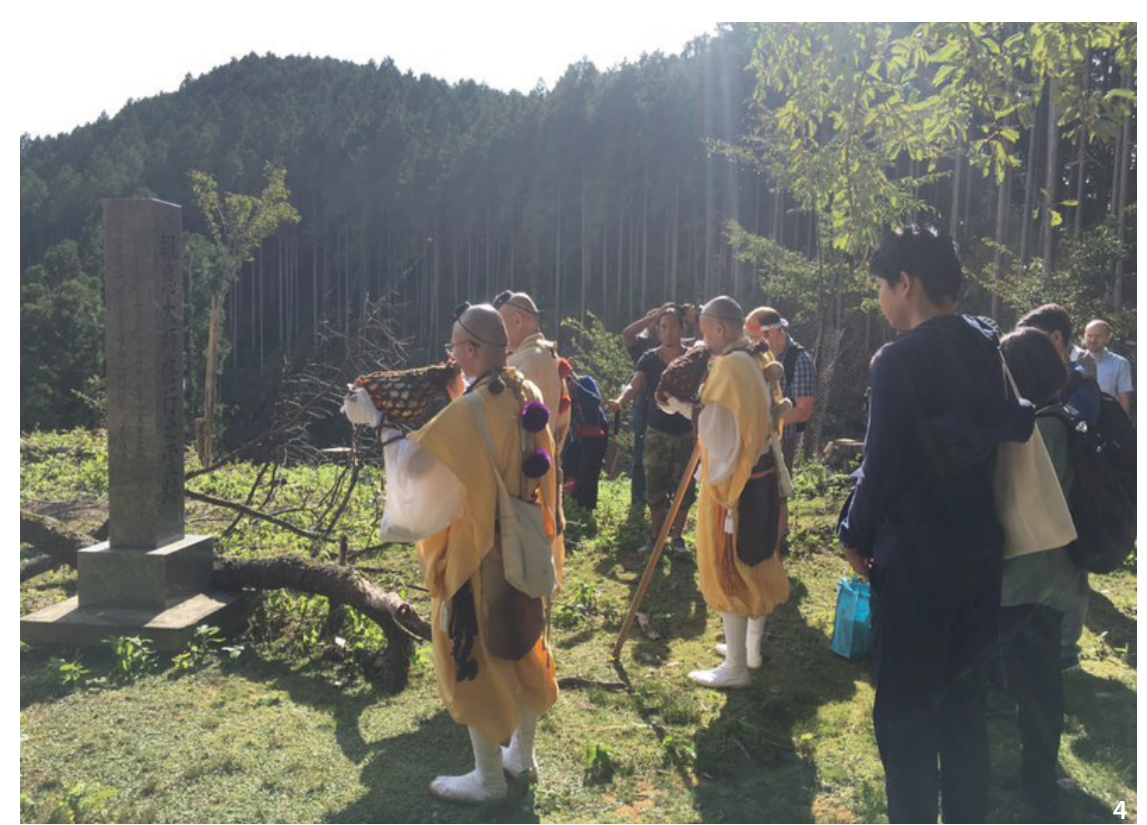

Figure 4 Shugendo pilgrimage, Kii Mountains (Source: the author).
The rice gods are invited to the farmer's house to spend the winter, and celebrate with traditional dishes prepared with local products, praying for a good harvest, and released back to the paddy fields when spring arrives. 'In the course of a whole ritual, the housemaster behaves as if an invisible deity of the rice field were actually there in front of him.' (from the nomination for inscription on the Representative List in 2009)

4. Pilgrimage Routes and sacred sites in the Kii Mountains The fourth example is the practice of Shugendo in the Kii mountains, in the Yoshino area, where a World Heritage Cultural Landscape, a national park and a BR overlap. Shugendo, a religion that combines Esoteric Buddhism and Shinto, focuses on the practice of climbing mountains as a purifying experience. Shugendo practitioners, called yamabushi, go through this pilgrimage to attain enlightenment and spiritual powers (Figure 4).

At all these heritage sites, satoyama and satoumi show the inter-connectedness of nature and culture, and how the practices and traditions related to these landscapes are grounded in the communities and a perception of landscape that involves time. These experiences teach that conservation of natureculture layers is grounded in daily life. The four cases show concrete examples of how international designations stem from local values.

However, these landscapes face challenges in the depopulation of rural areas as a consequence of a rapid urbanisation. The experience from this can be shared with other developed countries, and other rural areas around the world. Satoyama and satoumi are also being consumed by urban areas, and modernisation is impelling the loss of traditional and local knowledge, and the transformation of these landscapes. However, satoyama and satoumi can still be found remaining in the cities when paying attention to the climate, seasonal practices, persisting traditions, and concealed places where old shrines still stand.

\section{Reconnecting Nature and Culture in the HUL Approach}

To integrate the idea of linking nature and culture and trying to overcome the nature-culture divide in the field of heritage, this paper proposes that instead of focusing on divisions, we should think about relationships, wherein cultural and spiritual practices feed biodiversity and biodiversity feeds cultural and spiritual practices. Following the layering concept stated in the HUL approach, the focus would turn to mapping relationships as attributes following a transdisciplinary approach in which other sources of knowledge are integrated, such as indigenous and local knowledge. In this way, we can find the remains of satoyama and satoumi in our urban environments: as we identify and value the historical layering, we reveal the natural substratum that will support the development of quality and resilient environments.

Natureculture layers can be found in the historic urban landscape, even in a city such as Tokyo, with a population of more than 30 million in its metropolitan area, but where traditional festivals such as hanami (cherry blossom viewing) are performed and traditional seasonal foods still related to the satoyama and satoumi, from 
where the products are imported, are prepared. Shrines and temples still stand all over the city, even next to skyscrapers, maintaining spiritual values that make communities more resilient.

Therefore, to create a fourth-dimensional map of natureculture, we need to survey relationships, interactions and processes, grounding this knowledge in indigenous and local knowledge, involving the heritage holders and the people for whom places in the urban environment have significance.

In an increasingly migration-based urban environment, we need to look at the origins of inhabitants and create heritage networks that help us understand why something is valuable, and trace back to the source of its significance. Many of these traditions and this significance may be found in the ancestral relationship with their non-human environment.

To achieve SDG11 - planning and designing inclusive, safe, resilient and sustainable cities and human settlements-the indivisibility of nature and culture, and the urgent recognition of the value of our natureculture heritage based on community values need to be taken into account.

\section{Concluding Remarks}

This paper begins with discussion recalling the debate generated by the Anthropocene concept, which is already questioning when, where and if there is a separation between nature and culture:

In the early Anthropocene narrative, alteration of the environment, whether intentional or accidental, seems embedded in being human, as is the case for other successful species from leaf-cutter ants to tree-killing elephants. Such arguments are a counterpoint to the humannature dualism: By arguing that humans have always changed nature, there is no 'after nature' or 'end of nature' in the modern era (Malhi 2017, 25.13).

The question is, then, no longer if humans are part of nature, but if the concept of nature, as a separate entity, is still helpful for supporting sustainable dwelling of humans in this planet. The Anthropocene concept helps us see how far the nature-culture divide is deeply embedded in our understanding of human life.

This article demonstrates that the nature-culture divide is also reflected in the three international instruments fundamental for global action at a critical moment. This worldview needs to be overcome, so natureculture truly becomes a driver and enabler of sustainable urban development. In considering the importance of heritage for urban communities, the HUL approach is built upon in this paper and offers, as an alternative, the mapping of relationships, working beyond the divide of natural and cultural heritage. The rural Japanese cases of satoyama and satoumi provide examples of strong local connections between nature and culture. These connections serve as starting points for nature-culture linkage in cities.

The main lesson in satoyama and satoumi is that of resilient communities, which have maintained their heritage in their everyday practices, evolving and adapting to social, economic and environmental changes. Though some would disagree that the rural that reconnects us to nature is present in the urban, we need only look at the extent to which we focus on changing weather patterns and fluctuating seasons, which are our moreevident link with the non-human, and which inspire us to keep creating and recreating our heritage. Particularly in an increasingly vulnerable condition, in which we are threatened by the changing climate and proliferating disasters, it is fundamental to look back upon our rural heritage and decelerate the effects of our alienation from what we call nature, so as to find the way forward with urbanisation.

\section{Notes}

1. Author's translation from text in French.

2. See the World Conservation Congress in Hawaii, 2016 (https://www.iucn.org/sites/dev/files/n-c_wh_ journeys_programme.pdf), the ICOMOS General Assembly in New Delhi, 2017 (http://livinglandscapeobserver. net/culturenature-journey-new-delhi-india/), and the forthcoming US/ICOMOS Symposium in San Francisco, 2018 (http://www.usicomos.org/call-forpapersforward-together-a-culture-nature-journeytowardsmore-effective-conservation-in-a-changingworld/).

3. The MAB Programme was launched in 2000 by the MAB Urban Group to analyse the possibility of applying the BR concept to urban areas. See Frost's (2001) proposal for the UK, and Eastmann's (2003) proposal for the United States.

4. An example, in 2017, the São Paulo Green Belt was added to the Mata Atlântica BR established in 1992.

5. Several GIAHS-designated areas are also working with the Satoyama Initiative.

6. Author's translation from original text in French.

7. Author's translation from original text in French.

\section{References}


Agency for Cultural Affairs. 1950. "Japan Law for the Protection of Cultural Properties (Law No. 214, 1950) Amended."

Aprile, Helen, Gina Doubleday, and Michael Gibson, eds. 2015. Culture-Nature Links. World Heritage 75. Paris: UNESCO.

Araya Rosas, Pedro, and Miguel Clüsener-Godt, eds. 2010. Reservas de la Biosfera: su contribución a la provisión de servicios de los ecosistemas. Experiencias exitosas en Iberoamérica [Biosphere Reserves: Their Contribution to the Provision of Ecosystem Services. Successful experiences in Latin America]. Paris: UNESCO.

Bahuchet, Serge. 2017. Les Jardiniers de La Nature [Gardeners of Nature]. Paris: Odile Jacob.

Berliner, David, Laurent Legrain, and Mattijs Van de Port. 2013. "Bruno Latour and the Anthropology of Moderns." Social Anthropology/Anthropologies Sociale 21 (4): 435-447.

Berque, Augustin. 1976. Le Japon, gestion de l'espace et changement social [Japan, Space Management and Social Change]. Paris: Flammarion.

Berque, Augustin. 2001. Ecoumène. Introduction à l'étude Des Milieux Humanis [Ecumene, Introduction to the Study of Human Environments]. Paris: Belin.

Berque, Augustin. 2013. Thinking through Landscape. Abington: Routledge.

Borrini-Feyerabend, Grazia, Nigel Dudley, Tilman Jaeger, Barbara Lassen, Neema Pathak Broome, Adrian Philips, and Trevor Sandwith. 2013. "Governance of Protected Areas: From Understanding to Action." Best Practice Protected Area Guidelines Series, No. 20. Gland, Switzerland: IUCN.

Court, Sarah, and Gamini Wijesuriya. 2015. People-Centred Approaches to the Conservation of Cultural Heritage: Living Heritage. Rome: ICCROM.

Denevan, William M. 2001. Cultivated Landscapes of Native Amazonia and the Andes. New York: Oxford University Press.

Descola, Philippe. 2005. Par-Delà Nature et culture [Beyond Nature and Culture]. Paris: Gallimard.

Duraiappah, Anantha Kumar, Koji Nakamura, Kazuhiko Takeuchi, Masataka Watanabe, and Maiko Nishi. 2012. Satoyama-Satoumi Ecosystems and Human Well-Being: Socio-Ecological Production Landscapes of Japan. Tokyo: United Nations University Press.

Eastmann, Jennifer L. 2003. "Urban Biosphere Reserves: Integrating Conservation, Community and Sustainability." Wiliam \&Mary Environmental Law and Policy Review 27 (3): 707-753.
Feenberg, Andrew. 2013. "Lanthropologies et la question de la nature. réfléxions sur l'ecologie des autres, de philippe descola." [Anthropologies and the Question of Nature. Reflections on the Ecology of Others, by Philippe Descola.] Revue Du MAUSS 2 (42): 105-118.

FAO (Food and Agriculture Organization). 2017. Globally Important Agricultural Heritage Systems (GIAHS). Informational Package. Rome: FAO.

Frost, Pete. 2001. "Urban Biosphere Reserves: Re-integrating People with the Natural Environment." Town and Country Planning 70 (7/8): 213.

Ishizawa, Maya, Nobuko Inaba, and Masahito Yoshida. 2017. "Building Capacities in Asia and the Pacific: The Experience of the UNESCO Chair on Nature-Culture Linkages at the University of Tsukuba, Japan." The George Wright Forum 34 (2): 154-67.

Ishwaran, Natarajan, Ana Persic, and Nguyen Hoang Tri. 2008. "Concept and Practice: The Case of the UNESCO Biosphere Reserves." International Journal of Environment and Sustainable Development 7 (2): 118131.

IUCN, and ICOMOS. 2015. "Connecting Practice. Final Report.” IUCN, ICOMOS. Accessed December 11 2018. https://www.iucn.org/downloads/connecting_ practice_report_iucn_icomos_.pdf

Jokilehto, Jukka. 1999. A History of Architectural Conservation. Boston : Butterworth-Heinemann.

Latour, Bruno. 1993. We Have Never Been Modern. London: Longman.

Malhi, Yadvinder. 2017. "The Concept of the Anthropocene." Annual Review of Environment and Resources 42: 77-104.

Millenium Ecosystem Assessment. 2005. Ecosystems and Human Well-Being. A Framework for Assessment. Washington: Island Press.

NCB (Nature Conservation Bureau, Ministry of the Environment, Government of Japan). 2009. “The Satoyama Initiative. A Vision for Sustainable Rural Societies in Harmony with Nature." Ministry of the Environment, Government of Japan.

Orlove, Benjamin S., and Stephen B. Brush. 1996. "Anthropology and the Conservation of Biodiversity." Annual Review of Anthropology 25: 329-352.

Reed, Maureen G., and Merle M. Massie. 2013. "Embracing Ecological Learning and Social Learning: UNESCO Biosphere Reserves as Exemplars of Changing Conservation Practices." Conservation and Society 11 (4): 391-405.

Rössler, Mechtild. 2006. "World Heritage Cultural 
Landscapes: A UNESCO Flagship Programme 19922006." Landscape Research 31 (4): 333-353.

Smith, Laurajane. 2006. Uses of Heritage. Abington: Routeledge.

Takeuchi, Kazuhiko. 2003. Satoyama: The Traditional Rural Landscape of Japan. Tokyo: Springer.

Trzyna, Ted, Joseph T. Edmiston, Glen Hyman, Jeffrey A. McNeely, Pedro da Cunha e Menezes, Brett Myrdal, and Adrian Phillips. 2014. "Urban Protected Areas: Profiles and Best Practice Guidelines." Best Practice Protected Area Guidelines Series 22. Gland, Switzerland: IUCN.

UNESCO. 2011. "Recommendation on the Historic Urban Landscape." Accessed 11 December 2018. http:// whc.unesco.org/uploads/activities/documents/activity-638-98.pdf

UNESCO. 2012. "Culture: A Driver and an Enable of Sustainable Development. Thematic Think Piece." Accessed December 11 2018. http://www.un.org/millenniumgoals/pdf/Think\%20Pieces/2_culture.pdf

UNESCO. 2016. Culture Urban Future. Global Report on Culture for Sustainable Urban Development. Paris: UNESCO.

United Nations. 2015. "Transforming Our World: The 2030 Agenda for Sustainable Development.” Accessed December 11 2018. https://sustainabledevelopment. un.org/post2015/transformingourworld

United Nations. 2017. New Urban Agenda. Quito: United Nations.

United Nations. 2018. "World Urbanization Prospects: The 2018 Revision.” Accessed December 112018. https://population.un.org/wup/

United Nations General Assembly. 2010. "Outcome Document of the 2010 Millenium Summit, Keeping the Promise: United to Achieve the Millenium Development Goals, A/65/L.1." Accessed December 112018. http://www.un.org/en/mdg/summit2010/pdf/mdg\%20 outcome\%20document.pdf

Watsuji, Tetsuro. 1988. Climate and Culture: A Philosophical Study. USA: Greenwood Press/Yushodo Co. 